\title{
Exploring the Meaning of Therapeutic Horticulture for Anishinabek Youth in a Brief Residential Treatment Unit: A Community Engagement CSL Case Study
}

\author{
Michelle Uvanile, Connie Nelson, Judi Vinni, Rebecca Schiff
}

\begin{abstract}
AвSTRACT This paper explored community-university engagement that integrated a shortterm treatment facility for Indigenous youth, a social enterprise organization that focused on healing through horticulture therapy experiences and an interdisciplinary academic team. The focus was to discover whether a horticulture therapy (HT) approach held promise in terms of an appropriate way to expand community service-learning (CSL) with Indigenous peoples and to encourage more diversity of voices in community service-learning experiences. Youth participants took part in a photovoice study and further semi-structured interviews to document their perspectives on the meaning of their horticultural experiences. Findings revealed that youth valued the overall HT experience itself; being connected to the gardens and nature and the social interactions exploring spirituality and the self were significant and meaningful for them. Further, findings demonstrated that a collaborative partnership that engaged multiple service agencies to explore novel ways for engaging youth in healing activities with a university team that guided the research approach holds promise as a CSL with Indigenous youth. We conclude with recommendations on the significance of community-university engagement in delivering therapeutic horticulture programs for Indigenous youth as a community servicelearning initiative.
\end{abstract}

KeyWords community service-learning, youth, community-based research, Indigenous, horticultural therapy

\section{Land Acknowledgment: The catchment area of the Indigenous youth who participated in this community service-learning horticultural therapy experience includes Robinson Superior Treaty, Treaty 3, 5, and 9. The site of this research was on the traditional homeland of the Robinson Superior Treaty area.}

In the Engaged Scholar Journal's Spring 2018 issue, an emphasis was placed on situating the timeline for the emergence of Community Service-Learning (CSL) across Canada, assessing current approaches, and suggesting ways of broadening the scope of future CSL initiatives (Van Styvendale et al., 2018). The article's findings in that issue indicated that the J.W. McConnell Family Foundation's seed funding in 2005 had a notable impact on the uptake of CSL across Canada. This current paper emerged from one of the original ten McConnell-funded CSL 
initiatives (Kahlke \& Taylor, 2018). ${ }^{1}$ Further, this current paper builds on our food securitybased CSL experiences (Nelson \& Stroink, 2010, 2012, 2014; Harrison et al., 2013; Nelson, et al., 2005). We posit additional provisions for CSL through a case study of horticultural therapy (HT) where we could diversify CSL voices to include Indigenous youth (Fryer et al., 2007; Taylor et al., 2015).

While we are unaware of any previously published CSL initiative that has used an HT approach with Indigenous youth, there is substantive research on positive impacts from engaging in outdoor and nature-based activities for enhancing health and wellness (Beaulieu et al., 2018; Etherton, 2012; Hartig \& Marcus, 2006; Libman, 2007; Marcus \& Barnes, 1999; Pasanen et al., 2014; Okvat \& Zautra, 2011; Wardle, 2016; Wilson, 2018). Topics using a CSL approach have included eco-restoration projects, healing gardens in health care, participation in outdoor activities to promote health, and positive effects of nature activities for vulnerable children (Knackmuhs et al., 2017; Salam et al. 2019). Some of the key cumulative results have been that nature-based service-learning activities build empathy, foster a sense of perspectivetaking, promote problem-solving skills, enhance civic leadership, create a sense of 'rightness,' and help students find peace with oneself (Gellert et al. 2016). Critical elements for the success of CSL initiatives include listening to community members' needs, co-designing a plan, taking action together, and reflecting on the experience as lessons for future work together (Gellert et al., 2016). A limitation we noted in the published works has been a lack of involvement of Indigenous youth in service-learning activities in partnership with University researchers and local service agencies. Thus, in the research described in our paper, we aimed to uncover findings that may contribute to enhancing CSL for Indigenous youth.

We now turn to a brief look at HT using a Contextual Fluidity (CF) practice model, a description of the CSL partners and setting, and the methodology. We then describe and draw on the photovoice data to explore how this CSL horticulture therapy project impacted the Indigenous youth participants. We conclude by identifying ways that an HT approach to a CSL experience may help others broaden the scope of CSL experiences; thus, addressing the identified need for more attention to diversifying participants in Canadian-based CSL initiatives (Aujla \&

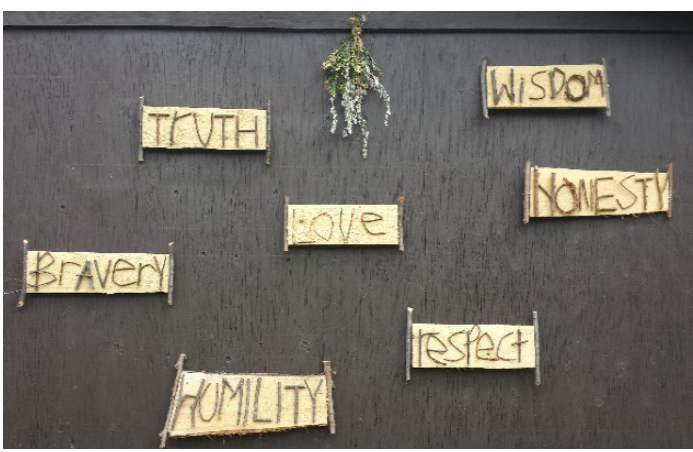

Figure 1. Anishabek seven grandfather teachings Photo credit: Judi Vinni, Willow Springs creative centre Zane, 2018).

\footnotetext{
1 Our journey began with receiving one of the ten J.W. McConnell Family Foundation Grants to educational institutions to study the research question of how a university could enhance their engagement with community through community service learning and community-based research (2006-2012).
} 


\section{Horticulture Therapy as a CSL}

Generally, the goals of horticultural therapy programs are to enhance one or all of the following faculties; that is, the "emotional, physical/sensory, social, cognitive/educational and [sense of] discovery/wonder/spirituality" (Fried \& Wichrowski, 2008, p. 76) while engaging in horticultural practices. As Hewson (2004) states, "what makes horticultural therapy unique is that it uses living material, requiring nurturing and care" (p. 1). Caring for plants helps one to assess and promote cognitive, physical, behavioural, and social skills. The very nature of an HT program is that it can engage all of the senses: taste, touch, smell, sound, and sight to produce food and beautify spaces. Thus, HT provides many learning opportunities to explore self, life, relationships, and their interconnectedness.

Therapeutic horticulture programs do not set out to label individual problems or define goals and desired outcomes. In some HT projects, positive regard is espoused for all life. Therefore, HT projects often encourage interconnected thinking, resonating with Indigenous, and more specifically, Anishinabek worldviews as participants in this project were from Anishinabek communities. This particular worldview recognizes that there are many ways of knowing, and certainty is not always necessary. In Anishinabek belief systems, the intuitive, spiritual, and organic ways of life can be accounted for and appreciated, and although not necessarily measurable, are no less true (Auger \& Pedri, 2009; Duran, 2006; Caduto \& Bruchac, 1995). Working from this position of appreciation of Indigenous worldviews, that is, that all life is interconnected, is integral in guiding the HT engagement when doing a CSL with Indigenous youth.

\section{Contextual Fluidity (CF)}

This community service partnership draws on a Contextual Fluidity practice model for introducing HT as a CSL (Nelson \& Stroink, 2020; Andree et al., 2014; Nelson \& McPherson, 2004). The CF model features an organic natural system's approach that embraces the reality that life is constantly in flux; from one moment to the next, it is fluid and ever-changing. CF supports the mutuality of the dynamic relationships among the youth participants, the HT leader from Willow Springs, and the staff at the treatment centre; in short, the community members involved in this CSL. Contextual Fluidity honours all participants' knowledge and recognizes the reciprocal and dynamic nature of respectful, supportive relationships. The CF practice model appears relevant for addressing challenges to well-being with Indigenous peoples with an emphasis on a holistic view of all participants and their spiritual, physical, emotional, and mental needs. Similarly, HT practices encourage a non-hierarchal and adaptable approach allowing for individuality and interconnectedness. Therapeutic horticulture practices innately offer opportunities to work from a CF practice model that espouses mutuality as a key facet. "Today I help you; tomorrow you may help me. Because I can help today does not give me any permanent right to feel superior or better; We all have things to contribute to the community" (Nelson \& McPherson, 2003, p. 94). 


\section{Engaged Partnership}

Our CSL-framed HT project draws on the strengths of relationships with community partners where service combined with learning allows for transformative experiences (Flecky, 2011). By focusing the CSL engagement on horticultural therapy recorded by the participants through photovoice, we are building a body of knowledge that is grounded in both theory and practice. This approach meets both of the original central McConnell aims of "capacity building for community organizations and in supporting the relationship between universities and the larger communities in which they are located" (Cawley, 2007, p. 1).

The partners included a social enterprise, not for profit organization, a local Indigenous youth treatment facility, and the local university. The catalyst for this relationship to emerge was a graduate student who had participated in some horticultural therapy training workshops with the not-for-profit organization, completed her undergraduate placement with the organization running the treatment facility, and had a university supervisor who was developing a practice model for helping particularly appropriate for Indigenous community service-learning initiatives. From this convergence, a genuinely reciprocal relationship emerged. Some key features of each partner are highlighted next.

\section{Willow Springs Creative Centre (WSCC)}

Emerging in 2002 through four women's efforts, the WSCC delivered in-house and mobile creative expression and therapeutic gardening programs to organizations, social service groups, schools, and the general public (Willow Springs, 2019). The WSCC approach has become the use of boreal forest resources that abound in the local setting to bring physical and mental health benefits to others by working with gardens, plants, and the unique northern landscape (Nelson et al., 2019). With over two decades of experience in HT, one of the founders was the catalyst for introducing youth to the HT experiences drawing on boreal forest and gardening resources readily accessible at the treatment centre.

\section{Dilico Anishinabek Family Care Treatment Centre}

Dilico Anishinabek Family Care's treatment home facility was eager to enhance its use of their natural setting in the boreal forest through their participation in horticultural programming. Their vision is balance and well-being for Anishinabek children, families, and communities; their mission to "embrace a holistic approach in the delivery of Health, Mental Health, Addictions and Child Welfare Services to complement the strengths, values, and traditions of Anishinabek children, families, and communities" (Dilico, 2011). The programs delivered at the treatment unit speak to this vision, and the introduction of a therapeutic horticultural program reflected this.

\section{Methodology}

\section{Immediate Built and Natural Setting}

The CSL project was located on-site at a treatment facility for youth experiencing emotional, behavioural, and family challenges. This facility is not publicly identified but appears from 
the street as an upper-middle-class home on several acres in a rural residential area. The area is surrounded by boreal forest, which provides privacy for the youth working in the raised bed vegetable garden and the medicine wheel garden, including native boreal forest plants. Each HT session was facilitated by the CSL graduate student and the HT instructor from Willow Springs. Each session typically began outdoors near the gardens with opportunities for the youth to share personal experiences. This sharing time was followed by opportunities to observe what was changing in the garden, like new plants growing, new insects, or identifying animals who had visited the garden like squirrels, rabbits, and deer. Voices of the Indigenous youth participants were encouraged through this non-didactic approach.

\section{Ethics}

This research was approved by the Lakehead University Research Ethics Board Romeo File No: 1461911. All parents, guardians, and youth were provided with a description of the research's nature and the reasons for participation. They were all provided with a cover letter and consent form written in age-appropriate language to ensure that participants understood their involvement, the nature of the research, as well as the reasons for participation.

\section{Participants}

The treatment facility's service area covers the Robinson-Superior Treaty area and parts of Treaties 3, 5, and 9 in Northwestern Ontario, Canada. Participants were of Cree, Ojibwe, or Oji-Cree descent. While most youth resided in Thunder Bay, Ontario, many had moved with their families within the past three years, originally coming from much smaller Northern Ontario communities. Two cohorts of Indigenous youth participated in the growing season May-September.

\section{Use of photovoice methodology}

Photovoice was utilized as the primary data collection method, followed by a semi-structured interview. A photovoice approach offers the opportunity for empowerment and is both recognizable and understandable for the participants. The use of a semi-structured interview is culturally relevant and age-appropriate for the participants ensuring that the descriptions and explanations of the lived experiences are accurate and understandable for the youth.

Children were provided with individual disposable cameras to freely take pictures throughout three therapeutic horticultural sessions of two hours each over June, August, and/ or September. They were encouraged to take photos of experiences that were meaningful to each participant. The use of photovoice engaged the participants as the experts within the context of their environment and thus place allowed for a deeper understanding of their perspectives on the HT experience. The semi-structured interviews acted as a follow-up to explore the motivations for, and meaning in each photo in more depth with each participant. When sharing the photos, an open leading question such as "Tell me about this picture: what was important for you to share in this picture?" This would then be followed up with probing questions. All semi-structured interviews were audio-recorded to ensure accuracy. 


\section{Findings}

Many themes emerged from the data revealing what was meaningful for the youth participants through the CSL experience: connection to place and culture; engaging social experiences; cognitive and behavioural benefits; skill building and creativity. Selected examples from the semi-structured interviews follow for each of these theme areas.

\section{Connection to place and culture}

The youth took photos demonstrating the importance of caring for one another and the land throughout this CSL program. Youth identified the ability to connect to their culture as the HT garden setting provided opportunities related to their Indigenous homeland experiences. One example:

Well when I heard the eagle I was like oh my god I haven't heard that in a long time. And I was just feeling, I was soo happy .... I was like, that's part of my culture. Well I felt really, really good and I felt proud because I hadn't heard that in a really long time.

One of the projects was to create a visual piece of artwork for the garden. Out of wood, hammers, and nails, an approximately four-foot-tall Thunderbird was constructed, painted, and hung in the trees near the garden. Both the activity of creating a thunderbird sculpture for the garden and the passive experience of it in the garden were meaningful.

The Thunderbird...it hooo, hooos neat. I don't know I just liked it because it had the four colours on there... This is a picture of my spirit thunderbird. I like my spirit from what it done here. Thank you.... like the eagle, the thunder... the thunderbird.

This was an opportunity for embracing Anishinabek culture, creating a sense of place and honour which seemed to resonate with the youth. One youth described the cultural significance of being in the outdoors and having the opportunity to connect with the Creator as important: "Well I liked it because I'm always happy to have seen the Creator, the Creator's living things that he has made, and we should all thank him and... and what the Creator has planned for us to see." Further to this the same youth also shared about another picture:

It's about us, we found an earthworm for our garden, which is really special because earthworms, they're really good for a garden and for us right now it was like a gift from the Creator for our garden, and we should all thank him. Now, our crops should be living better.

The delight and amazement in the experience of tasting the herbs and plants for the first time are evident in comments such as: "OH! This is the lemon balm. I tasted it just now. It 
was really good!"; "That's the mint right there. Mmmmmmm.”; "I was feeling great because the first time I heard that that was an apple tree - I got all excited when I heard that. Well, I love apples, as in apple pie."; "And the chocolate thing. The chocolate mint...it does taste like chocolate, and the other, um, mint thing...I don't know, it tastes good."; "It's about mint! I tasted it five times already...yaw, I tasted it another five times..."

The spirits of the children were high when the sense of taste was engaged. The process of growing food itself provided opportunities to embrace Anishinabek culture in the garden. The youth captured complex thought processes that demonstrated the broader ecosystem, the importance of culture, and the interconnectedness of life, in-line with an Anishinabek worldview. Learning that micro and macro life processes affected one another was also an example of understanding interconnectedness.

Many of the youth understood this through the teachings around the peony plant. The youth witnessed the plants and the insects in a symbiotic relationship, each needing the other: "Peony helps the ant; the ant helps the peony, and the peony helps the ant, and it [photo] was a close up of ants moving around on the peonies and helping out the peonies."

Recognizing that we all live together on the earth equally with all life — spiritual, physical, animal, insect and person - were also lessons from the garden and the children responded to this by taking pictures: "Yes the land is the animals' home and the plants are where the animals live and we planted lots of plants".

One child took a photo of the compost heap on the back of the grounds stating "I like that you guys are composting....it turns it into dirt". This demonstrated the invaluable lesson of returning to the land that you cannot use and the lifecycle and the value of the lesson that everything has a purpose. The natural world was in itself an incredible teacher in the lessons of resiliency.

The graduate students' field notes shared:

The beans that were so thoughtfully planted and cared for through the spring and then eaten by the deer seem to be making a reappearance... The perennial strawberry plants survived a cold winter only to be nibbled at by the deer throughout the spring, yet some survived much to the joy of the kids. This lesson was not lost on the kids as one photograph shows "the strawberries that made it through the winter" (Uvanile, 2012, p. 78).

Youth also came away from the program with behavioural benefits, learning the value of enjoying the fruits of the harvest when life was cared for and tended to and the consequences of when it was not. When plants survived, when cooking and crafts worked out, a sense of pride was felt. It was difficult for the children to share their disappointment when some of their seedlings died over the week when no one was watering them: 
What I learned about the earth...need to be watered every day. These are just all the dead plants. Weren't getting taken care of enough. And pumpkin... it's um, because it's bad....it died. Because they didn't have enough water.

These photos showed disappointment and learning and provided a teachable moment about caring for ourselves and the life around us. The youth learned to feel compassion for one another when things did not go according to plan. When they were making wood chimes, one of the tools had stopped working just when the last youth needed to complete her project. The horticulture staff member from Willow Springs was able to improvise a tool to complete the task at hand. While this particular youth was upset by this turn of events, all of the youth witnessed the resilience and problem-solving skills that led to success.

Learning through doing was the key. The youth embraced this method in the program. What was quite phenomenal about the learning and meaning-making experience in the garden was the number of pictures and comments that reflected the deeper feelings and understandings they shared. "(Name) never giving up on taking up the weeds" was shared by one participant who was able to conceptualize the value of "never giving up" and the implied importance of "taking up the weeds." Today (name) was able to face a fear of spiders. As we went to the bush he complained almost to the point of tears that he did not want to do it because of the bugs and spiders. Instead, once he participated in the willow building, he completely forgot his fear and his disposition changed.

\section{Engaging social experiences}

The opportunity for an engaging social experience that included room for humour and fun and opportunities for connection with and memories of family were significant for them. Throughout the program, the following words about their photos demonstrated how much

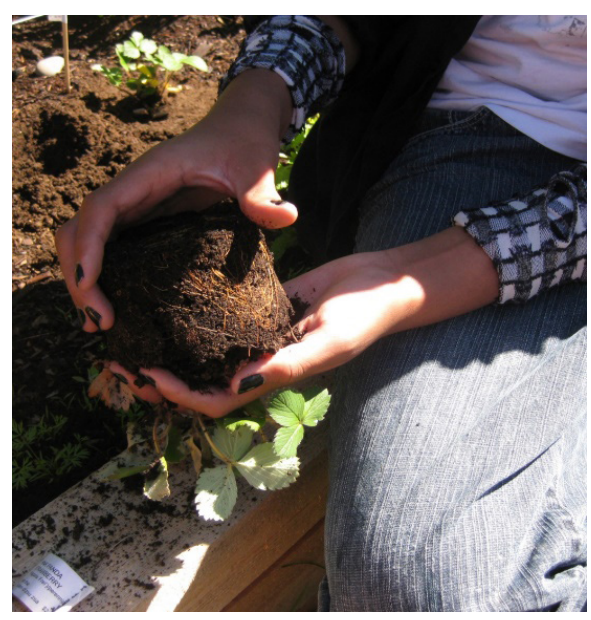

Figure 2. Transplanting strawberries Photo credit: Judi Vinni, Willow Springs Creative Centre the children loved to laugh and loved silliness and fun and games: "(Teacher name)... her being funny" and "They're doing something crazy!".

Humour seemed to capture their attention and came naturally to all of them. In the garden, imitations of animals ("She's all like, *imitates a chipmunk"; "Well he was making the antler look like a moose antler that's why... it was kind of funny") demonstrated the natural connection the children found between people and nature. They were so captured by their environment and the nature of the experience that many social challenges disappeared momentarily. They were a group working together, having fun. According to these youth, a therapeutic horticulture environment has room for antics, silliness, playfulness, and much laughter. 
One of the most photographed and talked-about subjects during the garden experiences was around social experiences. Comments arose, revealing an appreciation for companionship, fun, joy, cooperation, and acceptance. The gardening activities provided opportunities for exploration and working together to accomplish a common goal in a fun and appealing way. The youth's engagement was demonstrated with their quotes: "They're planting flowers. Yeah, and we're having a fun time too."; "Um, I also felt a little bit good that, um, things need teamwork."; "A group of kids... [we're] happy."

On a more sober note, the garden experience brought memories and connection to the Spirit world. While these children were away from their families, some had parents who passed away. The garden provided a place for them to feel close to their relatives and to connect with them. One youth shared that "I took a picture of this, it's a love thing 'cause it reminds me of my dad and how much I love him," while using her photograph to depict the wood and willow "Love" sign made by staff and placed in the garden. Another quote: "Love back there that made me think of my dad too."

For some, the distance felt greater, as was the situation of one youth whose mother had passed away. In her words, about her photo: “Um, lilies. And that's my favourite. My mom's favourite flower, and it's mine too... lots of fun things we used to do. You know, at the pow wow thing, um, at the cascades..."

From the graduate student's notes:

Today we had a significant moment we planted a blanket flower next to the flowers that were her Mom's favorite. The blanket flower was a reminder of "tucking in" and caretaking. It was a touching moment and a symbolic way for her to remember her Mom. She took such care in planting the blanket flower today, tenderly and quietly she worked. She was leaving this place knowing that these plants will stay together. The blanket flower and lilies shall remain in this garden side-by-side: A symbol of the new relationship for her and her Mom. (Uvanile, 2012, pp. 104-105)

Being in the garden situated by the bush also provided another youth with the opportunity to connect with her family's memories. This experience was able to help honour her family and develop a connection with them spiritually. As she stated, "Being in the bush was fun. It brings back memories...in my reserve. I always used to go to the bush with my grandparents. When they would go cut wood and then play in the snow or play in the bush."

\section{Skill building and creativity}

The youth also shared that they appreciated therapeutic horticulture activities providing skill-building, growth, and creativity opportunities. One of the youth commented on the importance of room for individual creativity within a group process: "I liked how everyone was doing their work and not copying everyone." The garden provided a place for the youth to find success and build skills. One participant stated that they "took a picture of the crops 
that we planted," demonstrating a sense of pride in the effort put forth and the achievement of creating something.

The nature of this programming allowed for constructive freedom to explore the garden and the nearby natural environment. This was intentional to allow for personal strengths, interests, and a natural curiosity to guide them. This also demonstrated trust and expectations of responsibility for the youth. One youth took a picture of how she and a friend chose to explore the bush and found a turtle in doing so. She showed how they enjoyed the opportunity to explore, be trusted, and have some freedom within the HT program.

The garden portion of the program offered opportunities for learning about biology and finding the wonder in nature. One youth took a picture of the seeds that came from a flower. She had not considered before the process from seed to life, to death and regrowth. She was thrilled to learn this process: "Oh yeah! Seeds! They came from the daisy."

The creativity and teamwork involved in building the willow fort were significant as the youth enjoyed designing the structure and its decorative features: "The weaving! Yes! I liked how me and Judi were doing it," and "Um, me and Judi and (name) worked on it. Uh, and we just thought it would be a cute door." This activity was also able to engage a youth who was initially resistant to the activity. She took a picture of it, stating, "It looks fancy!" and genuinely loved the result. It seems this activity, with its non-confrontational approach, demonstrated potential in engaging resistant participants.

When describing their photos, other youth responses included: "I took it because I like my class and I like my teacher," "I like the stuff you do here," "Me and you... because you are teaching us about the garden, I liked it," "I took a picture of you weeding because it was fun weeding with you," and "I like that you guys are teaching us about the garden and you guys are really fun to have." These all reflected the importance of relationships for them.

One youth playfully shared, "[You were] pulling, me pulling out the weeds...it was really fun so I took a picture of it." This statement seemed to demonstrate the joy and sense of appreciation for physical activity, skill-building, and being active outdoors. Another youth commented on his connection to caretaking through a dynamic physical process: "I helped put some of the soil on and put on the... what are those things called? The mulch...to stop roots or

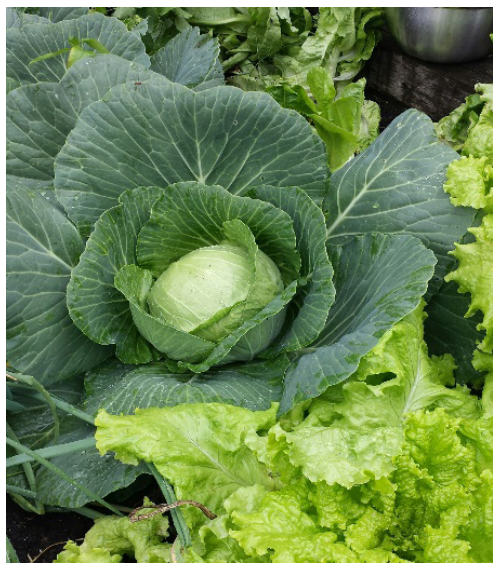

Figure 3. Autumn harvest Photo credit: J. Vinni Willow Springs Creative Centre prevent weeds."

\section{Discussion}

This CSL initiative provided an avenue for the youth to share their experiences within a therapeutic horticulture program and their meanings as participants ascribed to it. It offered insights into their world, which was important for them as only they could tell it. The overall 
experience for participants was one of enjoyment, engagement, and relevance.

In line with what Simson and Strauss (1998) stated as the primary focus of a social therapeutic horticulture program, the youth demonstrated feelings of self-esteem through their photographs. In this vein, "Activities can be designed to enhance creativity and self-expression" (Simson \& Strauss, 1998, p. 133). These youth articulated their appreciation of using their creativity and expression in the activities important to them.

At the beginning of each session, the research team could observe reluctance in the youth to get out into the garden. For the most part, this hesitancy disappeared once they found they were having fun with each other, learning about their world, and enjoying a laugh all while gaining a sense of accomplishment and success. Not only were they able to engage effectively with one other, but the youth were also able to build meaningful relationships with the facilitators and staff. They were able to develop respect, love, and caring for one another, their ancestors, the plants, the land, and themselves through this experience.

Photovoice and semi-structured interviews were chosen to gauge HT's impact on the Indigenous youth participating voluntarily in the short-term treatment program. Photovoice has been utilized successfully in research with vulnerable children where traumatic life experiences have made it challenging and often painful to express themselves verbally (Wardle, 2016; Aldridge, 2012). Photovoice provides the opportunity to empower youth to explore their social competencies and identities by being encouraged to take photos (Strack et al., 2004).

Our findings indicated that the overall HT experience itself, of being connected to the gardens, the social interaction, and the opportunity to learn new skills, explore spirituality and the self, which was meaningful. Data showed that the meaning was derived from the active and pragmatic activities connected to the gardens and nature as well as the crafts and cooking activities. Overall, photovoice did capture much of the meaning for the youth, and in any of the interviews, the youth were offered time to share any thoughts or reflections that weren't captured by the cameras but that meant something for them. All of them shared that they felt their photos were representative of their experience. Utilizing photovoice and semi-directed interviews as research tools were embraced by the youth. They commented many times on how much they liked using the cameras. The youth captured meaningful and relevant experiences for them in a way that was accessible given the diversity of individual participant capabilities.

They could share the meaning that they ascribed to the experience with their own words and images in terms of what the experience meant for them, not someone else; it is their reality that was captured. The evidence of the outdoors being an inspiration and offering opportunities for appreciation of natural beauty was a repeated observation. It seemed having a camera was novel and the youth were excited to have the cameras. As demonstrated in one girl's comment, passive experiences were also important too: "It felt nice. Like when you have the fresh breeze over you and the sun's on you and you get to take pictures with other people." Her experience reflected the benefits of being outdoors for a therapeutic experience. 


\section{Recommendations for horticultural therapy program attributes for future CSL}

We were enthusiastic about our experience in using horticultural therapy in a community service-learning initiative. We have offered a few recommendations on key HT program attributes and activities. These recommendations are grouped into four themes: sensory experiences; creativity and building on strengths; exploration and expression; families and culture.

\section{Sensory experiences}

Opportunities for sensory experiences were critical as the youth shared how the visual beauty, tastes, scents of nature, and the sounds of the experience captured their fascination and were enjoyed by them. In future HT initiatives, it seems essential to include foods, herbs, ornamental, and local boreal plant species to allow for many sensory activities and reflective lessons. Collecting seeds, harvesting, and cooking with the foods from the garden and nature are also recommended activities.

\section{Creativity and building on strengths}

Opportunities to express creativity through nature-based arts and craft activities and garden design allowed for individual interests and strengths to shine. These activities may promote success and skill-building as these were identified as important for the youth. Moreover, all programming can focus on adaptability to the cognitive and physical capabilities of the youth.

\section{Exploration and expression}

The youth shared that the experience must be fun, making space for humour, social engagement, and room for exploration within the garden. This included freedom for personal space and expression in activities. While some attention to time was appropriate, we found time boundaries should not be allowed to overly direct the activities. The program should be allowed to flow naturally with the energy level and interest of the participants; and thus, place priority on letting the interests of the youth guide the time and transition to HT activities. Often nature has things in store that are unplanned. It was essential to be open to unexpected opportunities and build on these unforeseen happenings. Our approach encouraged flexibility and adaptability for the youth. Some of the youth explained that this is the Creator's way of teaching us. You could not plan to see a frog in the garden, but when one appeared, as one youth shared, the Creator was showing that frog to us. He meant for us to see it and reflect on the lessons inherent in it.

\section{Families and culture}

Another significant recommendation for future programs was the importance of being able to include families or significant guardians and celebrate with them in a culturally meaningful way, such as with a feast. The nature of working through the medicine wheel garden and reflecting on the lessons it shared was also an essential element of connecting with culture. For some, this had more significance than for others, but there were valuable lessons for 
everyone regarding balance, wholeness, and interdependence. Connections to culture were important and required sensitivity and care. It was vital that the facilitator shaped the program based on the medicine wheel's lessons but not assume that all youth prescribed to traditional Anishinabek ways. As the partner facilitators played a key role in developing a comfortable, safe, and therapeutic environment, it is strongly recommended that the facilitators be attuned to the culture of place.

\section{Conclusion}

Based on our findings, horticulture therapy appears to hold promise in terms of an appropriate way to expand community service-learning with Indigenous peoples and thus encourage more voices in community service-learning experiences.

Findings demonstrated that the overall therapeutic horticulture experience itself, of being connected to the gardens and nature, the social interaction, and the opportunity to learn new skills, exploring spirituality and the self, was significant and meaningful for participants.

This CSL experience pointed to important considerations for future research and practice. In particular, it suggested that engaging social experiences, connection to place and culture, cognitive benefits, skill-building, and creativity may be important outcomes of horticultural therapy programs with Indigenous youth. Our findings also suggest that future community service-learning using horticultural therapy with Indigenous youth develop program approaches fostering sensory experiences, building on the significance of families and culture in the lives of youth, and encouraging creativity.

It is hoped that horticulture therapy approaches will be initiated in other community service-learning initiatives that will inform future CSL practice, decision making in funding programs such as these, and policy at all levels to support an approach that embraces Indigenous worldviews.

\section{About the Authors}

Connie Nelson (corresponding author), a professor emeritus from Lakehead University, contributes a long-standing and robust network of relationships with northern communities in areas of social capital, food security, and community well-being. Through her community service-learning engagements, she has developed a complexity-based helping process called Contextual Fluidity. Email: cnelson@lakeheadu.ca

Rebecca Schiff, an associate professor in the Department of Health Sciences at Lakehead University, has a long history of working closely with rural, remote, and Indigenous communities to investigate and research health issues and solutions, with a particular focus on intersections between health and sustainability. 
Michelle Uvanile has a master's degree in social work and completed her thesis focused on horticultural therapy with Anishinabek youth in residential treatment. Michelle has studied Horticultural Therapy with Mitchell Hewson, Master Horticultural Therapist, and led therapeutic horticulture programming for seniors in supportive housing. She is currently a social worker for people with complex needs.

Judi Vinni is the coordinator of Willow Springs Creative Centre and trained in horticultural therapy with Mitchell Hewson, Master Horticultural Therapist. She serves as a board member of the Canadian Horticultural Therapy Association. She has 12 years of delivering therapeutic horticultural programs for Anishinabek youth, children with Autism, and seniors in long-term care. Judi is presently developing a Grief Gardening program.

\section{References}

Andree, P., Chapman, D., Hawkins, L., Kneen, C., Muehlberger, C., Nelson, C., Pigott, K., QaderiAttayi, W., Scott, S., \& Stroink, M. (2014). Building effective relationships for communityengaged scholarship in Canadian food studies. Canadian Food Studies, 1(1), 27-53. https:// doi.org/10.15353/cfs-rcea.v1i1.19

Aldridge, J. (2012) The participation of vulnerable children in photographic research. Visual Studies, (27)1, 48-58. https://doi.org/10.1080/1472586X.2012.642957

Auger, D. \& Pedri, C. (2009). Anishinabek Culture. Dilico Anishinabek Family Care. https://www. dilico.com/article/anishinabek-culture-161.asp

Aujla, W., \& Hamm, Z. (2018). Establishing the roots of community service-learning in Canada: Advocating for a community-first approach. Engaged Scholars Journal, 4(1), 19-37. https:// doi.org/10.15402/esj.v4i1.306

Beaulieu, M., Breton, M., \& Brousselle, A. (2018). Conceptualizing 20 years of engaged scholarship: A scoping review. PLOS ONE, 13(2): e0193201. https://doi.org/10.1371/journal. pone.0193201

Caduto, M., \& Bruchac, J. (1995). Native Plant Stories told by Joseph Bruchac. Fulcrum Publishing.

Cawley, J. (2007). Community service-learning: Reflections for the foundation. https:// mcconnellfoundation.ca/

Dilico (2011)

Dilico Anishinabek Family Care. (2020). Assessment and brief treatment residential services. http:// www.dilico.com/article/assessment-and-brief-treatment-residential-services-126.asp

Duran, E. (2006). Healing the soul wound: Counselling with American Indians and other Native Peoples. Teachers College Press.

Etherington, N. (2012). Gardening for Children with Autism Spectrum Disorders and Special Educational Needs: Engaging with nature to combat anxiety, promote sensory integration and build social skills. Jessica Kingsley. 
Flecky, K. (2011). Foundations of service-learning. In K. Flecky \& L. Gitlow (Eds.), Service-learning in Occupational Therapy Education: Philosophy and Practice (pp. 1-18). Jones and Barlett.

Fried, G., \& Wichrowski, M. (2008). Horticultural therapy: A psychosocial treatment option. Primary Psychiatry, 15(7), 73-77.

Fryer, M., Wallis, R., Sattar, K., Annette, J., Battistoni, R., \& Lund-Chaix, A. (2007). Context and culture: Models of engagement around the world. In S. Gelmon and S. Billig (Eds.), From Passion to Objectivity: International and Cross-Disciplinary Perspectives on Service-Learning Research (pp. 3-18). Information Age.

Geller, J. D., Zuckerman, N., \& Seidel, A. (2016). Service-learning as a catalyst for community development: How do community partners benefit from service-learning? Education and Urban Society, 48(2), 151-175. https://doi.org/10.1177/0013124513514773

Harrison, B., Nelson, C.H., \& Stroink, M.L. (2013). Being in community: A food security themed approach to public scholarship. Journal of Public Scholarship and Higher Education, 3, 91110.

Hartig, T., \& Marcus, C. C. (2006). Essay: Healing gardens - Places for nature in health care. The Lancet, 368, S36-S37. https://doi.org/10.1016/S0140-6736(06)69920-0

Hewson, M. (2004). Horticulture as therapy: A practical guide to using horticulture as a therapeutic tool. Greenmore Printing.

Kahlke, R. \& Taylor, A. (2018). Community service-learning in Canada: One size does not fit all. Engaged Scholar Journal, 4(1), 1-18. https://doi.org/10.15402/esj.v4i1.305

Knackmuhs, E., Farmer, J., \& Reynolds, H.L. (2017). Student outcomes of eco-restoration servicelearning experiences in urban woodlands. Journal of Experiential Education, 40(1), 24-38. https://doi.org/10.1177/1053825916679182

Libman, K. (2007). Growing youth growing food: How vegetable gardening influences young people's food consciousness and eating habits. Applied Environmental Education and Communication, 6(1), 87-95. https://doi.org/10.1080/15330150701319388

Marcus, C. C., \& Barnes, M. (Eds.). (1999). Healing Gardens: Therapeutic Benefits and Design Recommendations. John Wiley \& Sons.

Nelson, C. H., \& Stroink, M. L. (2020). Understanding the dynamics of co-creation of knowledge: A paradigm shift to a complexity science approach to evaluation of community-campus engagement. Michigan Journal of Community Service Learning, 26(1). https://doi. org/10.3998/mjcsloa.3239521.0026.112

Nelson, C. H., Levkoe, C., Stroink, M. L., Kakagemic, R., McKay, E., Streutker, A., \& Stolz, W. (2019). Understanding social economy through a complexity lens in Northwestern Ontario: Four Case Studies. Canadian Food Studies, 6(3), 33-59. https://doi.org/10.15353/cfs-rcea. v6i3.357

Nelson, C. H., \& Stroink, M. L. (2014). Accessibility and viability: A complex adaptive systems approach to a wicked problem for the local food movement. Journal of Agriculture, Food Systems, and Community Development, 4(4), 191-206.

Nelson, C. H. \& Stroink, M. L. (2012). Hubs of knowledge creation: Exploring the potential for knowledge co-generation within the post-secondary academy Association of Commonwealth Universities. Interact, November 3.

Engaged Scholar Journal: Community-Engaged Research, Teaching, and Learning 
Nelson, C. H. \& Stroink, M. L. (2010). Benefits to students of service-learning through a food security partnership model. In J. Keshen, B. A. Holland, and B. E. Moely (Eds.), Research for What? Making Engaged Scholarship Matter (pp. 171-199). Advances in Service-Learning Research. Information Age.

Nelson, C. H., Stadey, M., \& Lyons, A. A. (2005). Community-academic research partnership: A key recipe for food security. In A. M. Kirbyson (Ed.), Recipes for Success: A Celebration of Food Security Work in Canada (pp. 27-31). Social Planning Council of Winnipeg.

Nelson, C. \& McPherson, D. (2004). Contextual fluidity: An emerging practice model for helping. Rural Social Work, (9), 199-208.

Nelson, C.H. \& McPherson, D. H. (2003). Cultural diversity in social work practice: Where are we now and what are the challenges in addressing issues of injustice and oppression? In Wes Shera (Ed.), Emerging Perspectives on Anti-oppressive Practice (pp. 81-100). Canadian Scholars Press.

Okvat, H. A., \& Zautra, A. J. (2011). Community gardening: A parsimonious path to individual, community, and environmental resilience. American Journal of Community Psychology, 47(34), 374-387. https://doi.org/10.1007/s10464-010-9404-z

Pasanen, T. P., Tyrväinen, L., \& Korpela, K. M. (2014). The relationship between perceived health and physical activity indoors, outdoors in-built environments, and outdoors in nature. Applied Psychology: Health and Well-Being, 6(3), 324-346. https://doi.org/10.1111/ aphw. 12031

Salam, M., Iskandar, D. N. A., Ibrahim, D. H. A., \& Farooq, M. S. (2019). Service-learning in higher education: A systematic literature review. Asia Pacific Education Review, 20(4), $573-$ 593. https://doi.org/10.1007/s12564-019-09580-6

Simson, S., \& Straus, M. (1998). Horticulture as Therapy: Principles and Practice. Food Products Press.

Strack, R., Magill, C. \& McDonagh, K. (2004). Engaging youth through photovoice. Health Promotion Practice, 5(1), 49-55. https://doi.org/10.1177/1524839903258015

Taylor, A., Butterwick, S., Raykov, M., Glick, S., Peikazadi, N. \& Mehrabi, S. (2015). Community Service-Learning in Canadian Higher Education. Open Collections. University of British Columbia Press.

Thompson, C. J., Boddy, K., Stein, K., Whear, R., Barton, J., \& Depledge, M.H. (2011). Does participating in physical activity in outdoor natural environments have a greater effect on physical and mental well-being than physical activity indoors? A systematic review. Environmental Science \& Technology, 45(5), 1761-1772. https://doi.org/10.1021/es102947t

Uvanile, M. (2012). A lived experience research: Exploring the meaning of therapeutic horticulture for Anishinabek youth in a brief residential treatment unit. Unpublished Master's thesis. Lakehead University. https://knowledgecommons.lakeheadu.ca/handle/2453/159

Van Styvendale, N., McDonald, J., \& Buhler, S. (2018). Community service-learning in Canada: Emerging conversations. Engaged Scholar Journal, 4(1), pp. i-ix). https://doi.org/10.15402/ esj.v4i1.303

Wardle, A. C. (2016). A Wilderness and Art Therapy Program for Children with Social Concerns. Honors Projects. 280. https://scholarworks.bgsu.edu/honorsprojects/280

Willow Springs Creative Centre. (n.d.). https://www.willowsprings.ca/

Wilson, R. (2018). Nature and Young Children: Encouraging Creative Play and Learning in Natural Environments. (3 $3^{\text {rd }}$ ed.). Taylor and Francis. 


\section{Appendix}

\section{Interview Guide Questions}

Guide for Photovoice Narrative Questions

1. How does this picture show what you enjoyed most about the garden?

2. How does this picture show what you enjoyed most about cooking?

3. How does this picture show what you enjoyed most about craft activities?

4. How does this photo show something meaningful for you when doing the crafts?

5. How does this photo show something meaningful for you when participating in the garden?

6 . How does this photo show something meaningful for you when you were cooking?

7. What does this photo show about what you have learned about yourself from this program?

8. What does this photo show about what you have learned about your identity from participating in this program?

9. What does this photo show about what you have learned about others from these activities? 10. What does this photo show about what you have learned about the land from these activities?

11. What was something that was difficult for you or that you didn't like while doing these activities. 